\title{
Nurse Practitioners' and Physicians' Views of NPs as Providers of Primary Care to Veterans
}

\author{
Carol E. Fletcher, S. Jill Baker, Laurel A. Copeland, Pamela J. Reeves, Julie C. Lowery
}

\begin{abstract}
Purpose: To describe NPs' and MDs' perceptions of the role of NPs, the degree of collegiality between professions, and NPs' feeling of acceptance, three relationship components that may affect the acceptance of NPs as providers of primary care.

Design and Methods: A descriptive study including both closed-and open-ended questions plus several Likert-type questions conducted June-August 2004. Our sample included all primary care NPs (87) and MDs (162) within a Midwestern Veterans Health Administration (VHA) region. Data were collected from 153 providers.

Findings: NPs saw their role as one of autonomous practice with physician back-up as needed, while MD respondents envisioned a role akin to a physician extender. Most of the physician respondents did not think NPs could provide adequate primary care to veterans who tend to have many comorbid conditions. Yet both groups considered their relationships to be collegial and most NPs felt accepted by physicians. MDs particularly valued NPs' teaching and interpersonal skills leading to greater patient satisfaction.

Conclusions: To facilitate the teamwork of NPs and MDs while improving utilization of NPs as primary care providers, VHA officials should routinely clarify roles, monitor quality of care of both MDs and NPs, and provide feedback to all concerned.
\end{abstract}

Journal of Nursing Scholarship, 2007; 39:4, 358-362. C2007 Sigma Theta Tau International.

[Key words: nurse practitioner, primary care, collaborative practice, veterans]

$\mathrm{T}$ he Veterans Health Administration (VHA), the largest integrated healthcare system in the US, is under intense pressure to provide high quality care to an increasing number of patients (currently 6 million) with a higher degree of medical complexity than in the general U.S. population (Morgan, Teal, Reddy, Ford, \& Ashton, 2005). An additional challenge for VHA comes with veterans returning from the wars in Iraq and Afghanistan, the number treated by VHA nearly doubling from 2005 to 2006 (Ephron $\&$ Childress, 2007) with up to 1 in 4 having mental health disorders (Seal, Bertenthal, Miner, Sen, \& Marmar, 2007).

\section{Background}

Within VHA, NPs are widely used to provide care, particularly since 1996 when a $200 \%$ increase in nonphysician primary care providers was mandated (Kizer, 1996). VHA routinely monitors the quality of primary care provided to its patients (Kizer, Demakis, \& Feussner, 2000); however, performance data are not separated by provider type. Potential benefits to VHA from the use of NPs include being able to provide care to more patients at the primary care level, and providing additional time for physicians to spend with more complex patients.

Despite these benefits and evidence from previous studies that the quality of care provided by NPs is equivalent to that provided by physicians (Aiken et al., 1993; Brooten et al., 2002; Horrocks, Anderson, \& Salisbury, 2002; Jacox,

Carol E. Fletcher, RN, PhD, Eta Rho, Research Health Science Specialist; S. Jill Baker, MA, MSW, Research Health Science Specialist; both at VA Healthcare System Ann Arbor, Ml; Laurel A. Copeland, PhD, Research Health Scientist, South Texas Veterans Health Care System, and Assistant Professor, University of Texas Health Science Center at San Antonio, Department of Psychiatry, San Antonio. Pamela J. Reeves, MD, Medical Director, Veterans Integrated Service Network 11; Julie C. Lowery, PhD, Associate Director, Center for Practice Management and Outcomes Research, both at VA Healthcare System, Ann Arbor, MI. This article is based on work supported by VISN 11 in Ann Arbor, Michigan, VERDICT Research Program at the South Texas Veterans Health Care System, San Antonio, Texas, and the Health Services Research \& Development Service of the Department of Veterans Affairs. Dr. Copeland is funded by VA HS\&RD award MRP-05-145. The views expressed in this article are those of the authors and do not necessarily represent the views of the Department of Veterans Affairs. Correspondence to Dr. Fletcher, VA Ann Arbor Healthcare System (11-H), Box 130170, Ann Arbor, MI 48113-0170. E-mail: cefletch@umich.edu

Accepted for publication August 9, 2007. 
1987; Laurent et al., 2005; Mundinger et al., 2000), the rate of use of NPs varies within the VHA. Conflicts over the role of NPs in other settings have been reported (Barton, 2006; Norris \& Melby, 2006; Stolee, Hillier, Esbaugh, Griffiths, \& Borrie, 2006), as has the finding that many MDs still wish to control the practice of NPs (American Medical Association, 2006; Japsen, 2007) or feel threatened by NPs' practice (Kowalczyk, 2007).

After an intensive effort, VHA reduced average waiting times for an appointment in primary care from 60.4 days to 28.2 days between 1999 and 2002 (Institute for Healthcare Improvement, 2005). But with increased numbers of veterans the challenge remains (Hopkins \& Adams, 2007). Given the need to improve veterans' access to primary care, it is imperative for VHA staff to understand potential barriers to the widespread adoption of NPs as primary care providers.

In their conceptual framework defining the factors affecting the implementation of evidence-based practice, Kitson, Harvey, \& McCormack (1998) defined human relationships as a key component. Based upon Kitson and colleagues' work, the purpose of this study was to describe NPs' and MDs' perceptions of the role of NPs, their degree of collegiality, and NPs' feelings of acceptance, three human relationship components that may be impeding the use of NPs as providers of primary care, despite the presence of substantial evidence indicating the provision of care equivalent in quality to that of MDs.

\section{Methods}

In this descriptive study NPs and MDs practicing chiefly in primary care in seven Midwestern VHA facilities were surveyed. Institutional review board approval was obtained before beginning the study. NPs and MDs were surveyed by mail June-August 2004. Physicians responded to 24 and NPs to 26 quantitative questions about NP responsibilities, relationships between the two professions, patient care routines, and demographic factors. The survey ended with four open-ended items (see Table), which are the focus of this manuscript. The responses to these questions offer important insights into the working relationships between NPs and physicians, and can provide useful information on how to improve these relationships. However, because it is impossible to determine the frequency of particular opinions from open-ended questions, the responses to several other questions are also presented to better understand the num-

\section{Table. Open-ended Survey Questions and Request for Comments}

1. Is there anything else that you would like to tell us so that we can understand your current and past practice as [with] an NP [NPs]?

2. What do you find most satisfying in your NP practice [in working with NPs]?

3. What do you find most difficult in your NP practice [practice with NPs]?

4. If you have any comments, please feel free to include them here. bers of respondents with opinions similar to those detailed in the open-ended questions.

The open-ended items were used to obtain detail on specific situations and perceptions which could not be obtained from the quantitative questions. This detail can enhance understanding of the rationale underlying responses to quantitative scales and, in turn, facilitate interpretation of the quantitative results (Creswell, 2005; Donovan et al,. 2002; Giacomini \& Cook, 2000).

The responses to the four open-ended survey questions were transcribed verbatim and checked for accuracy. Analysis of the responses was conducted by the first and second authors through an iterative and collaborative process to identify key concepts and derive a written coding scheme. Agreement of coding between the reviewers was checked (Miles \& Huberman, 1994). After re-review of the transcripts, the codes were reduced to categories, which were later grouped as themes. This process continued until consensus was reached regarding both the coding and definitions of the themes reflecting the primary study concerns (Crabtree \& Miller, 1999; Morse \& Richards, 2002).

Three of the quantitative questions addressed issues related to the open-ended questions-i.e., NPs' perceptions of their acceptance by physicians and administrators, the providers' subjective perceptions of the NP's role, and the relationship between NPs and MDs. These questions were analyzed by simple descriptive statistics (frequency distributions). The purpose of these questions was to determine prevalence of opinions rather than to measure a behavioral or emotional construct; hence no effort was made to establish construct or criterion validity for these items. Content validity was established by selecting items from previously published scales (Burman \& Steiner, 2002; Chambers, Deitrich, \& Resnik, 1986; DeNicola et al., 1994; Innerarity \& Kass-Wolff, 2002).

\section{Results}

Survey data were obtained from 74 NPs $(87 \%$ of those sampled), and 79 physicians ( $49 \%$ ) and included qualitative responses from 59 NPs ( $80 \%$ of those responding) and 50 physicians $(63 \%)$. Three themes identified in response to the open-ended questions are described below.

Roles of the NP. NPs reported working in a variety of roles with varying responsibility and independence. Several complained that their jobs were shifting from primary clinical work toward more administrative, managerial roles, or work that people with lesser training could fill. "Administrative staff does NOT understand NP clinical role." "I do not feel that I am ... using my education and expertise to the full extent."

In contrast, the physicians did not see a shift in NP roles. They described NPs working with a variety of clinical issues. Most referred to NPs as "assisting" or "collaborating." Only one specifically described NPs as working independently. 
Freeing-up the physician. Providing physicians time for other responsibilities was another theme related to the role of the NP. One rationale for using NPs in primary care is that physicians are more readily available to handle complex cases. Physicians who commented on the assumption of being "freed-up" were about equally divided on whether the NP presence lightened their load. The most common complaint among the MDs was that supervision of NPs required more work. "It does not reflect on any of my workload, the amount of time I spend supervising them." Only one NP observed that the physician did not get any extra administrative time for working with the NP. Some physicians complained that NP case loads were not equivalent to those of physicians, "They should be staffing more patients but they do not as I am too busy seeing my own patients." Others appreciated what NPs do. "NPs carry our panel of patients, seek aid from MDs only when they feel they need to.”

Clinical competence or independence. Competence was implied because the word "competent" was rarely used. The NPs' descriptions of implied competence was in two categories, (a) descriptions of their skills (process), and (b) descriptions of the results of their care (outcomes). One skillbased description referred to having worked with a second nurse to develop, "The first "nurse-run' hypertension clinic." Results-based descriptions included, "Being able to work hard and be successful in providing a level of care veterans value," "Patients who take my advice and do well, or if they don't (i.e., terminally ill patients), appreciate my efforts." However the NPs also perceived situations in which they knew they were not competent. "If I am to be given veterans outside my scope of practice the support system needs to be clearer."

Some of the physicians were quite positive about the NPs' competence. "I can't address every issue with our patients together. Fortunately my NPs are very competent." "In general they come here with a lot of pre-NP nursing skills and clinical acumen." In contrast, most of the physicians who commented on the NPs' competence tended to think that NPs were not qualified to manage a panel of complex patients without constant, direct MD supervision. Some thought that NPs lacked insight into their own limitations. "They do not know what they do not know."

Notably, when asked about NP strengths, physicians seldom remarked upon NPs' clinical skills and abilities. When they did, comments were generally limited to taking histories, medication reviews, and evaluation. The most common strengths noted by physicians were patient education activities, communication skills, taking time with patients and families, willingness to learn and be flexible, and traits such as a caring or helpful attitude. "Enthusiasm, genuine care, and patient advocacy. Patient satisfaction better than MDs." Most physicians emphasized the importance of NPs working within a limited scope of practice or caring for simple cases. "NPs are always the best working under direct supervision with doctors. They can be utilized best as case managers or seeing low complexity patients." Overall, physicians tended to see NPs as unsuited to the role of primary care clinician. Only two physicians stated they found NPs to be well qualified and competent for the tasks they were assigned.

Scale scores. Quantitative items were analyzed using descriptive statistics. On a 5 -point response scale, NPs reported feeling mostly or completely accepted by the physician administrator/medical director $(n=60 ; 82 \%)$ and by the physicians $(n=61 ; 81 \%)$. Both groups rated their working relationship as highly or usually collegial $(n=70,91 \%$ of physicians; $n=61,87 \%$ of NPs). Physicians were also asked to give an agree/disagree response to six statements. Fifty-eight $(78 \%)$ of MD respondents agreed that NPs are well integrated into "our" practice setting, but $42(58 \%)$ agreed that NPs care for patients who are too complex and $38(52 \%)$ affirmed that NPs are often assigned patients too complicated for the NPs' abilities (essentially raising the same issue twice using somewhat different wording). Twenty-one $(30 \%)$ agreed that NPs are responsible for too many patients while $16(23 \%)$ thought that NPs should be assigned more patients. However, $52(71 \%)$ also agreed that "all things considered, I am satisfied with the NPs in my practice.”

\section{Discussion}

With a mandated $200 \%$ increase in nonphysician primary care providers, a massive change in care delivery within the VHA was set into motion. NPs, the purveyors of this change, are themselves members of a young and evolving profession that some physicians view as a threat to their own practice and potential earnings.

The credentialing of NPs within the VHA contains a specific definition of their scope of practice including independent functioning and management of common acute illnesses. Yet mirroring the results reported in other studies, MDs generally said that NPs should focus on patients with chronic, rather than acute, illnesses and should not function too independently.

Both professions seemed to lack understanding of each other's concerns regarding the NP's role and relationship with MDs. The physicians did not notice that some NPs' roles were being shifted away from primary clinical work or that some NPs were being used in a manner not commensurate with their education and experience. Only one NP commented on the need for physicians to be given compensatory time to back up NPs when patients are beyond NPs' scope of practice. The physicians were concerned that NPs would practice without adequate supervision. The NPs were concerned that they would not be able to practice independently within their scope of training and experience.

The six agree/disagree statements for physicians show that a significant percentage of the respondents agree with the qualitative data suggesting some concern with NP rolei.e., NPs care for patients that are too complex or complicated. A minority were concerned about the number of patients NPs see, but the responses were split between those 
who say NPs are assigned too few patients $(23 \%)$, and those who think they are responsible for too many $(30 \%)$.

What was both surprising and encouraging about the study's findings was the degree of interprofessional collegiality judged to exist by both groups, the overall degree of satisfaction physicians felt with NPs in their practice, and the degree of acceptance that NPs stated they felt from both physicians and administrators despite negative comments expressed by many physicians. None of these findings have been previously reported. The physicians' negative comments may reflect lack of exposure to and interaction with NPs. Eighty-one percent of the MDs reported working $<17$ hours a week with an NP, while only $20(27 \%)$ stated they have worked with NPs regarding expansion of the NP role.

It was also encouraging that, in the written comments, some physicians expressed confidence in the practice of the NPs plus admiration for particular aspects of NPs' practice including care, advocacy, and education of patients-all important parts of the nursing paradigm promoting health rather than management of disease, ultimately resulting in better care outcomes for patients.

Study limitations include lack of assessment of reliability for the quantitative data. A 49\% physician response, as well as restriction to one geographic region of the country are also limitations. Still, this study of providers in three states yielded larger numbers of first-person observations, from both physicians and NPs, than did previous studies.

\section{Conclusions}

There appears to be a fine line between NPs' desires for autonomy and being pushed beyond their scope of practice in a large system with many complex patients. Meanwhile physicians want someone to reduce their workload without usurping their professional territory. These findings suggest a potential conflict between MD and NP perceptions of the NP role. As Kitson and colleagues (1998) propose, human relationships appear to be a key component affecting evidence-based implementation of NPs as providers of primary care. Positive relationships are fostered in the context of a learning organization where roles are clear and performance monitoring and feedback are routine.

VHA performance data are not currently separated by provider type. VHA, as well as other healthcare organizations interested in improving the utilization of nurse practitioners, need to collect data confirming the quality of care provided by NPs, accompanied by continued education of staff regarding NP performance and verifying what NPs are credentialed to do. Bolstered by the feelings of collegiality found between the professions, these actions could improve implementation of the policy within VHA, and in healthcare facilities in general, of using NPs as primary care providers in a collaborative environment. Given VHA's current challenges in providing primary care to an increasing number of veterans, and that some physicians apparently have con- cerns about the use of NPs as primary care providers, breaking down potential barriers within the organization to the acceptance of NPs is essential.

\section{References}

Aiken, L.H., Lake, E.T., Semaan, S., Lehman, H.P., O’Hare, P.A., Cole, C.S., et al. (1993). Nurse practitioner managed care for persons with HIV infection. Image: Journal of Nursing Scholarship, 25, 172177.

American Medical Association. (2006, June 13). AMA adopts measure to promote quality and safety at store-based health clinics. Retrieved August 2, 2006, from http://www.ama-assn.org/ama/pub/ category/16463.html

Barton, T.D. (2006). Clinical mentoring of nurse practitioners: The doctors' experience. British Journal of Nursing, 15(15), 820-824.

Brooten, D., Naylor, M.D., York, R., Brown, L.P., Munro, B.H., Hollingsworth, A.O., et al. (2002). Lessons learned from testing the quality cost model of advanced practice nursing (APN) transitional care. Journal of Nursing Scholarship, 34, 369-375.

Burman, M.E., \& Steiner, S. (2002). Practice profile of advance practice nurses in Wyoming. Wyoming Nurse, 15(2), 14-17.

Chambers, D.B., Deitrich, C.E., \& Resnik, B.A. (1986). 1986 Survey GNP Collaborative Evaluation Project. San Francisco, CA: University of California, School of Nursing.

Crabtree, B.F., \& Miller, W.L. (1999). Doing qualitative research. Thousand Oaks, CA: Sage.

Creswell, J.W. (2005). Educational research: Planning, conducting, and evaluating quantitative and qualitative research (2nd ed.). Upper Saddle River, NJ: Pearson.

DeNicola, L., Kleid, D., Brink, L., van Stralen, D., Scott, M., Gerbert, D., et al. (1994). Use of pediatric physician extenders in pediatric and neonatal intensive care units. Critical Care Medicine, 22(11), 1856-1864.

Donovan, J., Mills, N., Smith, M., Brindle, L., Jacoby, A., Peters, T., et al. (2002). Quality improvement report: Improving design and conduct of randomised trials by embedding them in qualitative research: Protec $T$ study. British Medical Journal, 5, 325(7367), 766-770.

Ephron, D., \& Childress, S. (2007, March 5). Forgotten heroes. Newsweek, 28-37.

Giacomini, M.K., \& Cook, D.J. (2000). Users' guides to the medical literature: XXIII. Qualitative research in health care: Are the results of the study valid? JAMA, 284(3), 357-362.

Hopkins, S.M., \& Adams, C. (2007, June 13). Lawmakers demand answers on VA waiting times. Retrieved July 5, 2007 from http://uschambercongress.illumem.org/meetnewcongress?action $=$ view NewsArticle\&documentID=2c9e4f6913244fbc011327970ffa0221.

Horrocks, S., Anderson, E., \& Salisbury, C. (2002). Systematic review of whether nurse practitioners working in primary care can provide equivalent care to doctors. British Medical Journal, 324(7341), 819823.

Innerarity, S., \& Kass-Wolff, J. (2002). A survey of advanced practice nursing in Texas: Characteristics and patterns of practice. Texas Nursing, $76(2), 12-13,15$

Institute for Healthcare Improvement. (2005). Veterans Health Administration spreads access improvements far and wide. Retrieved June 17, 2005, from http://www.ihi.org/IHI/Topics/Improvement/ SpreadingChanges/ImprovementStories/VeteransHealthAdministration SpreadsItsSuccessessFarandWide.htm

Jacox, A. (1987). The OTA Report: A policy analysis. Nursing Outlook, $35(6), 262-267$.

Japsen, B. (2007). Doctors push law on clinics in stores: Patients are put at risk, they contend. Retrieved May 7, 2007, from http://www.chicagotribune.com/business/chi-0705050028 may06, 1,4246005,print.story

Kitson, A., Harvey, G., \& McCormack, B. (1998). Enabling the implementation of evidence based practice: A conceptual framework. Qualitative Health Care, 7(3), 149-158.

Kizer, K.W., Demakis, J.G., \& Feussner, J.R. (2000). Reinventing VA health care: Systematizing quality improvement and quality innovation. Medical Care, 38(Suppl.), I7-I16. 
Kizer, K.W. (1996). Prescription for change: The guiding principles and strategic objectives underlying the transformation of the Veterans Health Care System. Washington, DC: Department of Veterans Affairs.

Kowalczyk, L. (2007). CVS seeks to open clinics in its stores-Would be first in state: Health officials cautious. Retrieved May 2, 2007, from http://www.boston.com/business/globe/articles/2007/05/02/cvs_seeks_to_ open_clinics_in_its_stores

Laurant, M., Reeves, D., Hermens, R., Braspenning, J., Grol, R., \& Sibbald B. (2005). Substitution of doctors by nurses in primary care (Cochrane Review). The Cochrane Library, Issue 2. Oxford, UK: Update Software. Miles, M.B., \& Huberman, A.M. (1994). Qualitative data analysis. Thousand Oaks, CA: Sage.

Morgan, R.O., Teal, C.R., Reddy, S.G., Ford, M.E., \& Ashton C.M. (2005). Measurement in veterans affairs health services research: Veterans as a special population. Health Services Research, 40(5, Part II), 15731583.
Morse, J.M., \& Richards, L. (2002). Read me first for a user's guide to qualitative methods. Thousand Oaks, CA: Sage.

Mundinger, M.O., Kane, R.L., Lenz, E.R., Totten, A.M., Tsai, W.Y., Cleary, P.D., et al. (2000). Primary care outcomes in patients treated by nurse practitioners or physicians: A randomized trial. JAMA, 283(1), 59-68.

Norris, T., \& Melby, V. (2006). The acute care nurse practitioner: Challenging existing boundaries of emergency nurses in the United Kingdom. Journal of Clinical Nursing, 15(3), 253-263.

Seal, K.H., Bertenthal, D., Miner, C.R., Sen, S., \& Marmar, C. (2007). Bringing the war back home: Mental health disorders among 103,788 US veterans returning from Iraq and Afghanistan seen at Department of Veterans Affairs facilities. Archives of Internal Medicine, 167(5), 476482.

Stolee, P., Hillier, L.M., Esbaugh, J., Griffiths, N., \& Borrie, M.J. (2006). Examining the nurse practitioner role in long-term care: Evaluation of a pilot project in Canada. Journal of Gerontologic Nursing, 32(10), 2836. 